\title{
EXPERIMENTAL RAMET AGGREGATION IN THE CLONAL PLANT AGROSTIS STOLONIFERA REDUCES ITS COMPETITIVE ABILITY
}

\author{
John P. M. Lenssen,,${ }^{1}$ Chad Hershock, ${ }^{2}$ Tanja Speek, ${ }^{1}$ Heinjo J. During, ${ }^{3}$ and Hans de Kroon ${ }^{1,4}$ \\ ${ }^{1}$ Department of Ecology, Radboud University Nijmegen, Toernooiveld 1, 6525 ED Nijmegen, The Netherlands \\ ${ }^{2}$ Department of Ecology and Evolutionary Biology, University of Michigan, Ann Arbor, Michigan 48109 USA \\ ${ }^{3}$ Department of Plant Ecology, F.A.F.C. Went Building, P.O. Box 800.84, NL-3508 TB Utrecht, The Netherlands
}

\begin{abstract}
Spatial models predict that long-distance dispersal of offspring provides competitive superiority in open environments. We tested this prediction by artificially aggregating ramets of the spreading clonal species Agrostis stolonifera in an undisturbed environment and in an environment where flooding increased open space. We compared the competitive response of this manipulated Agrostis with both the natural ramet distribution of Agrostis and with the naturally aggregated clonal species Alopecurus pratensis.

Our phenotypic manipulation of ramet dispersal significantly increased aggregation of clonal offspring, without altering the number of offspring, and thus provided an adequate test of spatial effects. Regardless of flooding, both Alopecurus and the aggregated Agrostis were more suppressed in species mixtures than the natural dispersed form of Agrostis. This demonstrates that long distance dispersal of ramets enhances competitive ability, at least in early stages of succession.
\end{abstract}

Key words: competition-colonization trade-off; disturbance; flooding; phenotypic manipulation; spatial pattern.

\section{INTRODUCTION}

Within plant communities, species usually have an aggregated distribution due to limited dispersal of sexual (Rees et al. 1996) and vegetative offspring (van der Hoeven et al. 1990). Many theoretical models have highlighted the importance of spatial distribution for competitive interactions and therefore on community dynamics (Schmida and Ellner 1984, Tilman 1994, Bolker and Pacala 1999, Bolker et al. 2003). Species aggregation may increase the number of intraspecific contacts relative to interspecific contacts and thereby allow coexistence instead of competitive exclusion (Neuhauser and Pacala 1999, Murrell et al. 2002). Thus far, these theoretical predictions have remained largely untested (Bolker et al. 2003), although both a field study (Rees et al. 1996) and an experiment (Stoll and Prati 2001) underlined the importance of spatial distribution for annual communities.

Very few studies have addressed the role of spatial distribution of clonal offspring, the prevalent form of propagation in many plant communities (de Kroon and van Groenendael 1997), on competition (Schmid and

Manuscript received 7 June 2004; revised 10 September 2004; accepted 7 October 2004. Corresponding Editor: S. E. Sultan.

${ }^{4}$ Corresponding author; E-mail: H.deKroon@ @ science.ru.nl
Harper 1985, Schmidt 1981 cited in Rejmanek 2002). The effects of aggregation may differ from those in annual plant communities because clonal growth is mainly in a lateral direction, which will affect the capacity for overtopping among clones (de Kroon et al. 1992). Spatially explicit models that specifically address clonal plants indicate that relatively long-distance dispersal of offspring is most favorable because it allows quick colonization and exploitation of open patches (Fahrig et al. 1994, Winkler et al. 1999). Once all patches are occupied, species with tight aggregation of ramets may become competitively superior, but only due to correlated life history traits such as physiological integration or shoot production rate (Winkler et al. 1999).

Comparing the competitive abilities of species (Schmid and Harper 1985, Lenssen et al. 2004), subspecies (Humphrey and Pyke 1998), or even genotypes (Cheplick and Gutierrez 2000) inevitably confounds aggregation with life history traits, because the evolution of shoot dispersal in clonal plants is tightly linked to these traits (Fischer and van Kleunen 2002). To avoid these confounding effects, we adopted phenotypic manipulation (Ackerly et al. 2000) by artificially increasing shoot aggregation of the stoloniferous 




Plate 1. "Tussocks" of the stoloniferous grass Agrostis stolonifera created by phenotypic manipulation. To experimentally increase aggregation of ramets, the linear stolons were lifted, wound around the planted ramet, and anchored to the ground. Photo credit: T. Speek.

species Agrostis stolonifera with dispersed ramets. In a previous experiment, Agrostis was a weak competitor relative to species with tightly aggregated ramets such as Alopecurus pratensis in undisturbed conditions but gained competitive superiority after flooding induced disturbance (Lenssen et al. 2004). Here, we address the hypothesis that this flooding-induced shift in competitive ability (throughout this paper defined as the ability to resist suppression by other species, i.e., "competitive response" sensu Goldberg [1990]) is related to the spatial ramet distribution in relation to open patches as created by flooding. Accordingly, we expect that increased ramet aggregation will decrease the competitive ability of Agrostis, at least under flooded conditions, and that aggregation alone will induce responses to competition and flooding that are similar to the naturally aggregated Alopecurus.

\section{Methods}

\section{Plant material}

Agrostis stolonifera L. and Alopecurus pratensis L. are common riverine grass species in the Netherlands. The former dominates the most frequently flooded parts of floodplain grasslands while the latter occurs at slightly higher elevations (Sykora et al. 1988, van Eck et al. 2004). Agrostis makes long linear stolons with vertical tillers emerging at the nodes. Alopecurus is a tussock species with tightly aggregated ramets. Vegetative material of both species was collected in floodplain grasslands of the River Waal in the Netherlands at 25 June 2002. We collected each species from a single population (both species: $51^{\circ} 53^{\prime} \mathrm{N}, 5^{\circ} 45^{\prime} \mathrm{E}$ ) but kept a minimum distance of $5 \mathrm{~m}$ between collected Alopecurus tussocks and Agrostis stolons to enhance genetic variation of our stock material. The collected material was vegetatively propagated three times while growing outdoors in 1-L pots with a 1:1 mixture of sand and potting soil. At the end of the growing season (9 September 2002), all plants were transferred into a controlled greenhouse at $\sim 20^{\circ} \mathrm{C}$ with additional lighting to extend the light period to $16 \mathrm{~h}$.

\section{Experimental design and phenotypic manipulation}

Our experimental setup followed a randomized block design with six blocks; each block having one replicate of a monoculture of each of three dispersal types ( $A l$ opecurus and manipulated and unmanipulated Agrostis) and an additive species mixture (containing all three dispersal types) for two flooding treatments, i.e., unflooded and 30 days of flooding. Because we used 


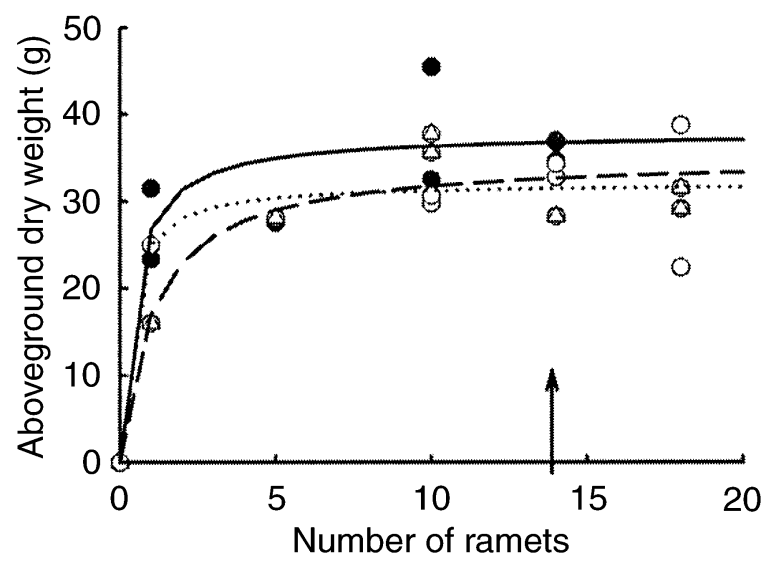

FIG. 1. Relationship between initial density and aboveground yield for Alopecurus (open triangles, solid line) and the dispersed (open circles, dotted line) and aggregated (solid circles, dashed line) dispersal types of Agrostis in unflooded conditions as determined in an additional experiment that was run simultaneously with the main experiment. Symbols show individual data points, and lines indicate the fitted yield-density curves. The vertical arrow indicates the density used in the monocultures of the actual experiment (14 ramets per tray).

separate trays for each monoculture and for the species mixture for each flooding treatment, our whole experiment required 48 trays.

Trays $(35 \times 22 \times 5 \mathrm{~cm}$ [length $\times$ width $\times$ depth] $)$ had two layers of antirooting cloth on the bottom and were filled with $4 \mathrm{~L}$ of humus-rich black soil that was thoroughly mixed with $11 \mathrm{~g}$ of osmocote slow release (3-4 mo) grains containing 15\% N, 11\% P, 13\% K, and $2 \% \mathrm{Mg}$. To prevent interference with neighboring trays, we placed each tray into a larger container with edges up to $9 \mathrm{~cm}$ above the top of the trays. Trays assigned to the same block were placed together on a bench in the same greenhouse as used during pretreatment. Within each block, the position of trays was rerandomized every two weeks. Three times a week, we watered all trays with tap water until field capacity. Eighteen weeks after transplanting tillers to the various trays, we harvested the experiment.

The experiment included two dispersal types of Agrostis, hereafter referred to as Agrostis-aggregated and Agrostis-dispersed. Agrostis-aggregated refers to plants with experimentally increased aggregation of ramets, realized by gently lifting the spreading stolons from the ground surface and winding them around the mother ramet, i.e., the initially planted tiller. The position of stolons was fixed by anchoring them to the ground with iron climbing wire. This resulted in "tussocks" of Agrostis that obtained a maximum diameter of approximately $6 \mathrm{~cm}$ (observed in unflooded monocultures; see Plate 1). This repositioning of stolons and modules was carried out three weeks after planting and a second time 10 weeks after planting.

In order to rule out possible side effects due to manual touching of plants and anchorage to the ground, we followed similar procedures for Agrostis-dispersed, except that we did not change the position and orientation of stolons in this treatment. To assess whether there was any impact of our interference on Agrostis productivity, we also planted six monoculture trays with Agrostis that were left untouched and were not flooded. Comparisons of aboveground dry mass in these trays with aboveground dry mass in the unflooded monocultures of Agrostis-aggregated and Agrostis-dispersed revealed no significant differences between the three categories $\left(F_{2,15}=0.570, P=0.577\right)$.

\section{Competition and flooding treatments}

The competition treatment followed an additive design with, initially, 14 tillers per tray for each in monoculture and mixture. As a consequence, the total initial density in mixtures was $3 \times 14$ tillers. The difference in total density between monocultures and mixtures may be problematic if density in monocultures is below the saturation part of the yield-density curve, because this would imply that a difference between monocultures may be due to both changes in intra- and interspecific competition (Sackville Hamilton 1994). In a parallel experiment in which we measured final yield of different initial densities for each of the three dispersal types, final yield stabilized at densities that were much lower than the monoculture density of 14 tillers per tray (Fig. 1).

We assigned each tiller to a separate cell that was randomly selected from a grid of $10 \times 6$ cells placed over an inner rectangular surface $(30 \mathrm{~cm}$ length $\times 18$ $\mathrm{cm}$ width) of the tray. We took care that tillers from the same genotype, i.e., originating from the same fieldcollected tussock or stolon, ended up in different trays.

In mixtures, tillers of different dispersal types were marked with differently colored toothpicks, mainly to distinguish Agrostis assigned to the "aggregated" and "dispersed" treatment. Because initial size differences may affect the outcome of short term competition experiments (Grace et al. 1992) we standardized the size of all planted ramets by cutting shoots and roots to a common $10 \mathrm{~cm}$ shoot length and $4 \mathrm{~cm}$ root length.

Six weeks after the planting of monocultures and species mixtures, trays assigned to flooding treatments were totally submerged for 28 days. We choose this flooding duration because a previous experiment showed a reversal in competitive ability between Agrostis and Alopecurus after this duration without a significant difference in mortality due to flooding (Lenssen et al. 2004). Flooding was applied in three circular basins $($ diameter $\times$ depth $=180 \times 90 \mathrm{~cm})$ that were placed 
in the same greenhouse as the unflooded trays. We filled each basin with nonchlorinated tap water and used Daphnia sp. and a filtering system to prevent growth of algae in the water. Each basin contained trays from two blocks. Immediately after flooding we returned the flooded trays to the benches and placed them among the unflooded counterparts from the same block for the remaining two months.

Temperature and oxygen concentration were measured weekly within each basin with a YSI model 54 sensor with a Pt/Au electrode (YSI, Yellow Springs, Ohio, USA). Water temperature remained within the range $18.3-20.3^{\circ} \mathrm{C}$ and the oxygen concentration was $9.37 \pm 0.11 \mathrm{mg} / \mathrm{L}$ (mean $\pm 1 \mathrm{SE}$, pooled across censuses and basins). Simultaneously, we determined light transmission through the water layer by measuring light intensity at the water surface and at $5 \mathrm{~cm}$ above the bottom of the basin (at plant height) with a cosinecorrected underwater quantum sensor (model LI192SB; LI-COR, Lincoln, Nebraska, USA) connected to a quantum-photometer (model LI-185SB; LI-COR). About half $(51 \% \pm 2 \%)$ of the incident light was transmitted through the water layer.

\section{Data collection}

To monitor spatial distribution of ramets in monoculture and mixtures we placed a grid of $10 \times 6$ cells, each $3 \times 3 \mathrm{~cm}$, over each tray and counted all rooted ramets of Alopecurus and all rooted nodes of both Agrostis dispersal types in each cell. This was repeated three times during the experiment: one week before flooding, one week after flooding, and at the end of the experiment, two months after flooding.

For each census, tray, and dispersal type we analyzed patterns in the distribution of ramets with Moran's I (Upton and Fingleton 1985), indicating the degree of autocorrelation for all possible pairs of quadrats at a certain distance from each other. We determined Moran's $I$ values for spatial lags up to three cells, but we only present values for adjacent cells (i.e., distance lag $=1$ ) because this scale gave the maximum degree of spatial autocorrelation.

The shoot counts in each separate cell also allowed us to calculate the abundance of each dispersal type, in each tray at each census, as the total shoot number. To obtain a second abundance measure, we harvested all living aboveground plant material at the end of the experiment and subsequently measured dry mass after drying at $70^{\circ} \mathrm{C}$ for at least $48 \mathrm{~h}$. To reduce edge effects, we only harvested within an inner rectangular surface of similar dimensions ( $30 \mathrm{~cm}$ length $\times 18 \mathrm{~cm}$ width) as used for shoot counts.

\section{Data analysis}

We used a type I ANOVA (Norusis 1999) to test the effects of block, dispersal type, competition, and flood- ing on spatial distribution (Moran's $I$ ), number of rooted ramets, and aboveground biomass. Block was considered as a random factor and all other terms were considered fixed. Significant main and interactive effects with dispersal type were further decomposed into two nonorthogonal contrasts to test Agrostis-dispersed vs. Agrostis-aggregated and to compare both aggregated dispersal types, i.e., Alopecurus against Agrostisaggregated. For each individual contrast, significance levels were adjusted to $\alpha^{\prime}=0.025$ following the DunnSidák method (Sokal and Rohlf 1995). Shoot number and aboveground dry mass were natural-log-transformed to achieve homogeneity of variances and normal distribution of residuals (Sokal and Rohlf 1995), but Moran's I data required no transformation. Because Moran's $I$ and shoot number were measured repeatedly in the same trays during the experiment, we included census as a within-subject effect in repeated-measures analysis of variance with Greenhouse-Geisser-adjusted degrees of freedom.

\section{REsults}

Spatial patterns

Spatial aggregation of ramets resulted in a strong correlation between ramet numbers of adjacent cells, as quantified by high Moran's I values. Moran's I was significantly higher for Agrostis-aggregated than for Agrostis-dispersed (Fig. 2 and "dispersed vs. aggregated" contrast within dispersal type in Table 1), which indicates that our manipulation of stolon position had worked as intended. There were no significant interactions of competition or flooding with the Agrostis dispersal types (Table 1) and it may therefore be concluded that the difference between both Agrostis dispersal types was consistent across treatments.

Compared to the naturally aggregated species Alopecurus, the aggregated form of Agrostis had a higher degree of shoot aggregation. This difference was most pronounced after flooding and later on in the experiment, as also suggested by the significant contrast within the flooding $\times$ dispersal type $\times$ time interaction (Table 1).

\section{Plant responses}

With regard to shoot numbers, both Agrostis dispersal types showed similar responses to competition and flooding (Table 1). Shoot numbers of both were strongly reduced by competition and experienced weaker reductions under flooding (Fig. 3). Only in unflooded monocultures did shoot numbers differ between both dispersal types, but this difference was not consistent during the experiment. The aggregated form had more ramets after 10 weeks, whereas the dispersed type had most ramets at the end of the experiment (Fig. 
Unflooded


Flooded


FIG. 2. Spatial autocorrelation of the number of rooted ramets between adjacent cells, calculated with Moran's $I$ (mean $\pm 1 \mathrm{SE}, n=6$ ) for Alopecurus (solid triangles), Agrostis-dispersed (open circles), and Agrostis-aggregated (solid circles) in unflooded and flooded monocultures (mono) and species mixtures (mix). Spatial distribution was recorded six weeks after planting, immediately after flooding $(10 \mathrm{wk})$, and at the end of the experiment (18 wk). The vertical bars indicate the least significant difference $(P<0.05)$.

3). This temporal shift in unflooded monocultures explains the significant contrast within the highest order interaction term (Table 1).

However, with respect to aboveground biomass there was a significant effect of Agrostis dispersal type in response to competition (Table 1). Aboveground biomass in monocultures did not differ between both Agrostis dispersal types, but regardless of flooding, the aggregated form produced less biomass than the dispersed form when growing with interspecific neighbors (Fig. 3).
Relative to Agrostis-aggregated, Alopecurus had a consistently lower number of ramets (Fig. 3). While the difference in shoot number between both aggregated dispersal types altered with competition and time (Table 1), these factors only affected the extent to which Agrostis-aggregated exceeded Alopecurus (Fig. 3). In terms of biomass, the naturally aggregated Alopecurus displayed a similar response to competition as indicated by the insignificant Alopecurus- vs. Agrostis-aggregated contrast with competition (Table $1)$. 
TABLE 1. $F$ values and their significance for effects of block, flooding, competition, and dispersal type on spatial aggregation of ramets (Moran's I) and (natural-log-transformed) ramet number and aboveground dry mass.

\begin{tabular}{|c|c|c|c|c|}
\hline Source of variation & df & Moran's I & $\begin{array}{l}\text { Ramet } \\
\text { number }\end{array}$ & Dry mass \\
\hline Block (B) & 5,55 & 0.38 & 0.66 & 0.80 \\
\hline Flooding (F) & 1,55 & 0.27 & $10.72 * *$ & $81.02 * * *$ \\
\hline Competition (C) & 1,55 & 0.01 & $271.59 * * *$ & $200.68 * * *$ \\
\hline Dispersal type (D) & 2,55 & $4.58 *$ & $158.84 * * *$ & $6.20 * *$ \\
\hline Agrostis: aggregated vs. dispersed & 1,55 & $9.14 * *$ & 1.30 & $8.11 * *$ \\
\hline Alopecurus-vs. Agrostis-aggregated & 1,55 & 2.70 & $255.18 * * *$ & 0.42 \\
\hline $\mathrm{F} \times \mathrm{C}$ & 1,55 & 0.30 & $19.48 * * *$ & 0.99 \\
\hline $\mathrm{F} \times \mathrm{D}$ & 2,55 & 0.28 & 1.70 & 0.31 \\
\hline $\mathrm{C} \times \mathrm{D}$ & 2,55 & 1.43 & $4.25 *$ & $5.93 * *$ \\
\hline Agrostis: aggregated vs. dispersed & 1,55 & & 1.77 & $11.23 * *$ \\
\hline Alopecurus-vs. Agrostis-aggregated & 1,55 & & $8.47 * *$ & 0.58 \\
\hline $\mathrm{F} \times \mathrm{C} \times \mathrm{D}$ & 2,55 & 1.76 & 0.52 & $2.80 \dagger$ \\
\hline Residual (MS) & 55 & 0.07 & 0.09 & 0.09 \\
\hline Time $(\mathrm{T})$ & 2,110 & $53.08 * * *$ & $464.00 * * *$ & \\
\hline Block $\times$ time & 10,110 & 0.21 & 1.07 & \\
\hline $\mathrm{F} \times \mathrm{T}$ & 2,110 & 2.35 & $9.16^{* * * *}$ & \\
\hline $\mathrm{C} \times \mathrm{T}$ & 2,110 & 0.17 & $19.82 * * *$ & \\
\hline $\mathrm{D} \times \mathrm{T}$ & 4,110 & 1.67 & $7.81 * * *$ & \\
\hline Agrostis: aggregated vs. dispersed & 2,110 & & $10.55 * * *$ & \\
\hline Alopecurus- vs. Agrostis-aggregated & 2,110 & & $8.88 * * *$ & \\
\hline $\mathrm{F} \times \mathrm{C} \times \mathrm{T}$ & 2,110 & 0.95 & $3.64 *$ & \\
\hline $\mathrm{F} \times \mathrm{D} \times \mathrm{T}$ & 4,110 & $2.60 *$ & $2.71 *$ & \\
\hline Agrostis: aggregated vs. dispersed & 2,110 & 1.56 & 1.65 & \\
\hline Alopecurus-vs. Agrostis-aggregated & 2,110 & $4.09 *$ & 1.14 & \\
\hline $\mathrm{C} \times \mathrm{D} \times \mathrm{T}$ & 4, 110 & 0.26 & 1.77 & \\
\hline $\mathrm{F} \times \mathrm{C} \times \mathrm{D} \times \mathrm{T}$ & 4,110 & 0.26 & $3.48 *$ & \\
\hline Agrostis: aggregated vs. dispersed & 2,110 & & $6.41 * *$ & \\
\hline Alopecurus-vs. Agrostis-aggregated & 2,110 & & 2.51 & \\
\hline Residual (MS) & 110 & 0.03 & 0.05 & \\
\hline
\end{tabular}

Notes: Moran's I and ramet number were determined at three consecutive censuses ("time"), and time was therefore analyzed as a within-subject repeated factor. Their significance levels are based on to Greenhouse-Geisser adjusted degrees of freedom. Significant main and interaction terms with dispersal type were further decomposed into two nonorthogonal contrasts to compare both Agrostis types with each other ("Agrostis: aggregated vs. dispersed") and to compare both aggregated types (Alopecurus-vs. Agrostis-aggregated).

$\dagger$ Marginally significant, $P<0.1$; $* P<0.05$ (or $P<0.025$ in case of contrasts); ** $P<$ $0.01 ; * * * P<0.001$.

\section{DISCUSSION}

To our knowledge, there is one other study with clonal plants that compared aggregated and random distribution (Schmid and Harper 1985) in which only the initial pattern was varied. We repeatedly modified the position of Agrostis ramets allowing us to explicitly address the effect of spatial distribution of offspring on competitive interactions. Our phenotypic manipulation was successful because it resulted in a significantly higher degree of aggregation in species mixtures, the treatment where we intended to test the effect of aggregation. Moreover, our treatment left shoot production rate or biomass production unaffected. By changing positions of (vegetative) offspring independent from number of offspring our study thus meets the requirements for a test of endogenous spatial effects (Bolker et al. 2003).

Our results show consistently higher biomass production for the natural dispersed form than the aggre- gated form of Agrostis in mixtures, and thus underline the importance of space for competitive interactions of perennial plants (de Kroon et al. 1992, Silvertown et al. 1994, Law et al. 1997, Pineda-Krch and Poore 2004). Spatial models predict that long-distance dispersal, as in the natural form of Agrostis, provides a favorable strategy if recurrent disturbance maintains open patches (Fahrig et al. 1994, Winkler et al. 1999, Bolker and Pacala 1999). We therefore expected an advantage for the dispersed form of Agrostis over both the aggregated Agrostis and Alopecurus particularly after flooding. Instead, dispersed ramet distribution produced a competitive advantage both under flooded and unflooded conditions. It is possible that the limited time span of our experiment has played a role. Although flooding created significantly more open cells, at the start of the experiment the amount of empty space was similarly high in the flooded and unflooded treatment (results not shown). The many open cells early in the 




\section{Flooded}
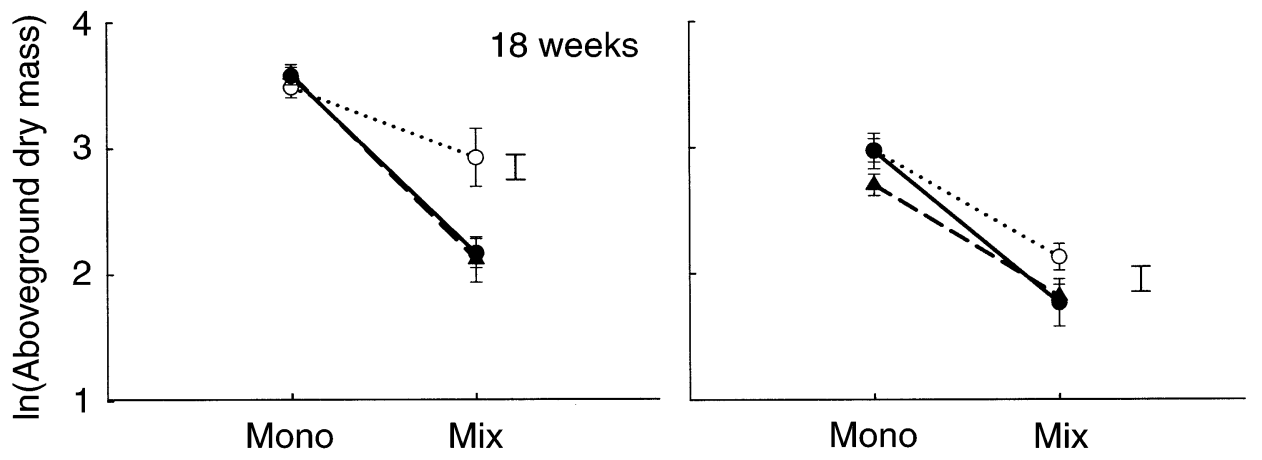

FIG. 3. Total number of rooted ramets immediately after flooding (top and middle panels) and aboveground dry mass (bottom panels; all are natural-log-transformed values, mean $\pm 1 \mathrm{sE}, n=6$ ) for Alopecurus (solid triangles), Agrostisdispersed (open circles), and Agrostis-aggregated (solid circles) in unflooded and flooded monocultures (mono) and species mixtures (mix). The figure shows the number of ramets immediately after flooding (10 wk) and ramet number and aboveground biomass at the end of the experiment (18 wk). The vertical bars on the right-hand side of each panel indicate the least significant difference $(P<0.05)$.

experiment will have provided initial benefits to the dispersed form in both treatments. Although our yield density curves (Fig. 1) indicated that maximum yield had been reached at the end of our experiment, at least in non-flooded mixtures, an initial advantage for the dispersed type may have resulted in benefits preserved until the end of the experimental period. This explanation is consistent with our previous experiment in which we found that competitive superiority of Alopecurus did not develop until the second growing season (Lenssen et al. 2004). Other experiments indicate a similar time lag before aggregated forms emerge as superior competitors (Schmid and Harper 1985, Humphrey and Pyke 1998), unless the experiment starts in very dense vegetation (Cheplick 1997).

In combination with earlier work (de Kroon et al. 1992, Rees et al. 1996, Stoll and Prati 2001), our study strongly suggests that effects of spatial distribution of offspring depend on the vegetation structure. At high density, increased aggregation enhances competitive ability by increasing the amount of intraspecific relative to interspecific contacts (de Kroon et al. 1992, Rees et 
al. 1996, Stoll and Prati 2001). Our results indicate that at low density, spatial dispersal rather than aggregation, confers a higher competitive ability. While consistent with predictions from spatially explicit models (Tilman 1994, Fahrig et al. 1994, Bolker and Pacala 1999. Winkler et al. 1999, Bolker et al. 2003), this is to our knowledge the first experiment that altered spatial distribution of (clonal) offspring independent from the number of offspring (reviewed by Bolker et al. 2003). We demonstrated that spatial dispersal of Agrostis ramets enhances performance in low-density mixtures. Since Agrostis is a weak competitor relative to aggregated species in the long run (Lenssen et al. 2004), our results suggest that the competition-colonization tradeoff (Tilman, 1994, Bolker and Pacala 1999) also applies to clonal propagation.

\section{ACKNOWLEDGMENTS}

We thank H. van de Steeg, A. Smit-Tiekstra, and W. van Eck and for their practical support.

\section{Literature Cited}

Ackerly, D. D., S. A. Dudley, S. E. Sultan, J. Schmitt, J. S. Coleman, C. Randall Linder, D. R. Sandquist, M. A. Geber, A. S. Evans, T. E. Dawson, and M. J. Lechowicz. 2000. The evolution of plant ecophysiological traits: recent advances and future directions. BioScience 50:979-995.

Bolker, B. M., and W. S. Pacala. 1999. Spatial moment equations for plant competition: understanding spatial strategies and the advantages of short dispersal. American Naturalist 153:575-602.

Bolker, B. M., W. S. Pacala, and C. Neuhauser. 2003. Spatial dynamics in model plant communities: what do we really know? American Naturalist 162:135-148.

Cheplick, G. P. 1997. Responses to severe competitive stress in a clonal plant: differences between genotypes. Oikos 79: 581-591.

Cheplick, G. P., and C. M. Gutierrez. 2000. Clonal growth and storage in relation to competition in genets of the rhizomatous perennial Amphibromus scabrivalvis. Canadian Journal of Botany 78:536-546.

de Kroon, H., T. Hara, and R. Kwant. 1992. Size hierarchies of shoots and clones in clonal herb monocultures: do clonal and non-clonal plants compete differently? Oikos 63:410 419.

de Kroon, H., and J. van Groenendael. 1997. The ecology and evolution of clonal plants. Backhuys Publishers, Leiden, the Netherlands.

Fahrig, L., D. P. Coffin, W. K. Lauenroth, and H. S. Shugart. 1994. The advantage of long-distance clonal spreading in highly disturbed habitats. Evolutionary Ecology 8:172187.

Fischer, M., and M. van Kleunen. 2002. On the evolution of clonal plant life histories. Evolutionary Ecology 15:565582

Goldberg, D. E. 1990. Components of resource competition in plant communities. Pages 27-49 in J. B. Grace and D. Tilman, editors. Perspectives on plant competition. Academic Press, San Diego, California, USA.

Grace, J. B., J. Keough, and G. R. Guntenspergen. 1992. Size bias in traditional analyses of substitutive competition experiments. Oecologia 90:429-434.
Humphrey, L. D., and D. A. Pyke. 1998. Demographic and growth responses of a guerilla and a phalanx perennial grass in competitive mixtures. Journal of Ecology 86:854-865.

Law, R., T. Herben, and U. Dieckmann. 1997. Non-manipulative estimates of competition coefficients in a montane grassland community. Journal of Ecology 85:505-517.

Lenssen, J. P. M., H. M. van de Steeg, and H. de Kroon. 2004. Does disturbance favour weak competitors? Mechanisms of changing plant abundance after flooding. Journal of Vegetation Science 15:303-312.

Murrell, D., D. Purves, and R. Law. 2002. Intraspecific aggregation and species coexistence-response from Murrell, Purves and Law. Trends in Ecology and Evolution 17:211.

Neuhauser, C., and S. W. Pacala. 1999. An explicitly spatial version of the Lotka-Volterra model with interspecific competition. Annals of Applied Probability 9:1226-1259.

Norusis, M. J. 1999. SPSS for Windows. Release 10.0. SPSS, Chicago, Illinois, USA.

Pineda-Krch, M., and A. G. B. Poore. 2004. Spatial interactions within modular organisms: genetic heterogeneity and organism fitness. Theoretical Population Biology 66: 25-36.

Rees, M., P. J. Grubb, and D. Kelly. 1996. Quantifying the impact of competition and spatial heterogeneity on the structure and dynamics of a four-species guild of winter annuals. American Naturalist 147:1-32.

Rejmanek, M. 2002. Intraspecific aggregation and species coexistence. Trends in Ecology and Evolution 17:209-210.

Sackville Hamilton, N. R. 1994. Replacement and additive designs for plant competition studies? Journal of Applied Ecology 31:599-603.

Schmid, B., and J. L. Harper. 1985. Clonal growth in grassland perennials. I. Density and pattern-dependent competition between plants with different growth forms. Journal of Ecology 73:793-808.

Shmida, A., and S. Ellner. 1984. Coexistence of plant species with similar niches. Vegetatio 58:29-55.

Silvertown, J., C. E. M. Lines, and M. P. Dale. 1994. Spatial competition between grasses: rates of mutual invasion between four species and the interaction with grazing. Journal of Ecology 82:31-38.

Sokal, R. R., and F. J. Rohlf. 1995. Biometry, the principles and practice of statistics in biological research. Third edition. Freeman, San Francisco, California, USA.

Stoll, P., and D. Prati. 2001. Intraspecific aggregation alters competitive interactions in experimental plant communities. Ecology 82:319-327.

Sykora, K. V., E. Scheper, and F. van der Zee. 1988. Inundation and the distribution of plant-communities on Dutch river dikes. Acta Botanica Neerlandica 37:279-290.

Tilman, D. 1994. Competition and biodiversity in spatially structured habitats. Ecology 75:2-16.

Upton, G. J. G., and B. Fingleton. 1985. Spatial data analysis by example. Volume I. Point pattern and quantitative data. Wiley, Chicester, UK.

van der Hoeven, E. C., H. de Kroon, and H. J. During. 1990. Fine-scale spatial distribution of leaves and shoots of two chalk grassland perennials. Vegetatio 86:151-160.

van Eck, W. H. J. M., H. M. van de Steeg, C. W. P. M. Blom, and H. de Kroon. 2004. Is tolerance to summer flooding correlated with distribution patterns in river floodplains? A comparative study of 20 terrestrial grassland species. Oikos 107:393-405.

Winkler, E., M. Fischer, and B. Schmid. 1999. Modeling the competitiveness of clonal plants by complementary analytical and simulation approaches. Oikos 85:217-233. 